We suggest that by means of head positioning a flexible, curved tip suction catheter may be placed reliably in the right or left main bronchus of intubated newborns. By this means, selective bronchial suctioning or lavage can be carried out easily without the need for bronchoscopy or radiographic screening facilities.

\section{References}

1 Whitfield NM, Douglas Jones M. Atelectasis associated with mechanical ventilation for hyaline membrane disease. Crit Care Med 1980;8:729-32.

2 Wyman ML, Kuhns LR. Lobar opacification of the lung after tracheal extubation in neonates. J Pediatr 1977;91: 109-12.
3 Brandstater B, Muallem M. Atelectasis following tracheal suction in infants. Anesthesiology 1969;31: 468-72.

4 Bush GH. Tracheobronchial suction in infants and children. Br J Anaesth 1963;35:322-6.

5 Gregory GA. Respiratory care of newborn infants. Symposium on recent clinical advances. Pediatr Clin North Am 1971;19:311-24.

6 Anthony JS, Sieniewicz DJ. Suctioning of the left bronchial tree in critically ill patients. Crit Care Med 1977;5:161-2.

Correspondence to $\mathrm{Dr} M$ Silverman, Department of Paediatrics and Neonatal Medicine, Hammersmith Hospital, Ducane Road, London W12 0HS.

Received 27 June 1983

\title{
Hypoxanthine guanine phosphoribosyl transferase deficiency presenting with gout and renal failure in infancy
}

\section{P C HOLLAND, M J DILlON, J PINCOTT, H A SIMMONDS, AND T M BARRATT}

Renal Unit, The Hospital for Sick Children, Great Ormond Street, and Purine Laboratory, Guy's Hospital, London

SUMMARY A month old infant had gout and renal failure caused by hypoxanthine guanine phosphoribosyl transferase (HGPRTase) deficiency. Investigations showed a high uric acid value, crystal nephropathy on ultrasound, and uric acid deposition on renal biopsy. The HGPRTase value was low in red cells and fibroblasts.

The Lesch-Nyhan syndrome ${ }^{1}$ caused by hypoxanthine guanine phosphoribosyl transferase (HGPRTase) deficiency $^{2}$ usually presents in late infancy or early childhood with self mutilating behaviour and retarded development, but in young adults with the milder form of the disease urolithiasis and renal impairment have been reported. ${ }^{3}$ Although this clinical picture is rare in infancy, we describe a child aged five weeks who presented with gout and renal failure, and emphasise the problems encountered in diagnosis and treatment.

\section{Case report}

A baby boy, the first child of healthy unrelated parents, was born at 39 weeks' gestation, after a normal pregnancy, and weighed $3 \cdot 2 \mathrm{~kg}$. From age three weeks he fed poorly and was excessively irritable. On admission to hospital, irritability was confirmed and the interphalangeal joints of the first, second, and third fingers of the left hand were red, swollen, and obviously painful (Fig. 1). Abdominal examination was normal, blood pressure was $95 / 65$ $\mathrm{mmHg}$, and examination of the central nervous system showed mild hypotonia with normal neonatal reflexes. A maternal grandfather had suffered

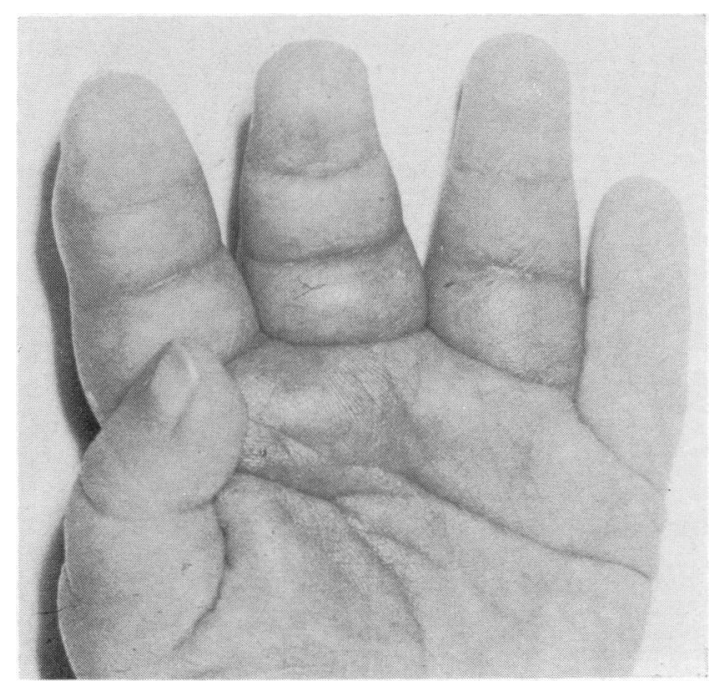

Fig 1 Swollen interphalangeal joints of the 1st, 2nd, and 3rd fingers of the left hand. 
from kidney stones, but there was no other family history of renal disease.

Investigations showed a plasma creatinine value of $350 \mathrm{umol} / 1(3.9 \mathrm{mg} / 100 \mathrm{ml})$, urea $37.4 \mathrm{mmol} / 1$ $(6.25 \mathrm{mg} / 100 \mathrm{ml})$, bicarbonate $14 \mathrm{mmol}(\mathrm{mEq}) / \mathrm{l}$, calcium $2.69 \mathrm{mmol} / 1(10.8 \mathrm{mg} / 100 \mathrm{ml})$, phosphate $3.84 \mathrm{mmol} / 1(11.9 \mathrm{mg} / 100 \mathrm{ml})$, uric acid 1.13 $\mathrm{mmol} / 1(19 \mathrm{mg} / 100 \mathrm{ml})$, and haemoglobin $8 \cdot 7$ $\mathrm{g} / \mathrm{dl}$. Routine examination of the urine showed $1+$ of protein, a trace of blood, and urate crystals on microscopy. The urine uric acid was $0.34 \mathrm{mmol} / 24 \mathrm{~h}(57 \mathrm{mg} / 24 \mathrm{~h})$. The urine uric acid to creatinine ratio $(1 \cdot 17)$ and the hypoxanthine/ xanthine ratio $(1 \cdot 3)$ were both within the normal range for age. A plain abdominal radiograph was normal but ultrasound showed bilateral bright renal echo patterns suggestive of a crystal nephropathy. An open renal biopsy (Fig. 2) showed extensive tubular atrophy and tubular epithelial giant cell transformation. Cryostat sections examined under polarised light showed crystals in the tubules and interstitium that dissolved on fixing in formalin.

Enzyme investigations showed negligible HGPRTase activity in both lysed and intact red cells and in skin fibroblasts (Table), confirming that HGPRTase deficiency was the cause of gout and renal failure. Heterozygote values were found in the mother's fibroblasts only, and other family members were normal.

Initial treatment was sodium bicarbonate and

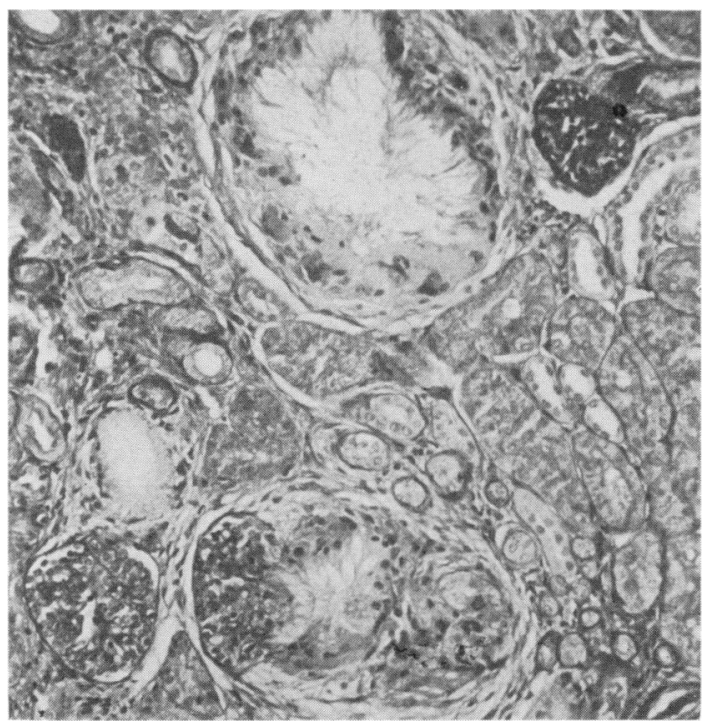

Fig. 2 Renal biopsy showing extensive tubular atrophy and giant cell formation. Uric acid crystals are not seen as they were dissolved on processing.
Table Hypoxanthine guanine phosphoribosyl transferase activity in intact red cells and lysed red cells

\begin{tabular}{llll}
\hline Sample & $\begin{array}{l}\text { Intact red cells } \\
(\% \text { nucleotide formed })\end{array}$ & $\begin{array}{l}\text { Lysed red cells } \\
(\text { nmol/mgHb/h) }\end{array}$ & $\begin{array}{l}\text { Fibroblasts } \\
\text { nmol/mg } \\
\text { protein/h }\end{array}$ \\
\hline Patient & $<0 \cdot 2$ & $<0.01$ & 0.9 \\
Mother & not done & 101 & 17 \\
Control & $>90$ & $80-130$ & $63-82$ \\
\hline
\end{tabular}

aluminium hydroxide and subsequently allopurinol in a dose of $10 \mathrm{mg} / \mathrm{kg} / \mathrm{day}$. The gout and excessive irritability improved considerably over the next few weeks and the plasma creatinine value fell to 90 $\mu \mathrm{mol} / 1(1.01 \mathrm{mg} / 100 \mathrm{ml})$. At 18 months the child remained hypotonic and showed mild dystonic movements but no self mutilation. The subsequent dosage of allopurinol was adjusted on the basis of serum urate values and oxipurinol excretion.

\section{Discussion}

This report shows that HGPRTase deficiency should be considered as a possible cause of renal failure in infancy-particularly when more common abnormalities have been eliminated. The clinical recognition of gout may clearly be useful but the early diagnostic clue from ultrasound examination, suggesting an underlying crystal nephropathy deserves special mention. The histological appearance of urate nephropathy may be missed if cryostat sections are not examined under polarised light. Anaemia may be associated with HGPRTase deficiency. Although it has been reported as megaloblastic in a few patients, it often occurs in association with renal failure and, as in this child, is indistinguishable from the anaemia of chronic renal failure. The anaemia subsequently improved on recovery of renal function.

The plasma urate was high for the degree of renal failure suggesting over production. The urine uric acid and urine hypoxanthine/xanthine ratios were, however, normal, owing to the renal failure which may lead to diagnostic confusion as these values are characteristically high in HGPRTase deficiency.

This patient emphasises the difficulty in heterozygote detection. The mother's status was identified by fibroblast studies only, and the lack of other affected family members suggests a new mutation.

HGPRTase deficiency may not result in the full spectrum of striking neurological signs of the Lesch-Nyhan syndrome. Previous reports have shown both minor and severe neurological problems with HGPRTase values $<1-30 \% \%^{4-6}$ but the hypotonia and very low intact red cell enzyme activity in this child suggests a poor prognosis for neurological development. 


\section{References}

1 Lesch M, Nyhan WL. A familial disorder of uric acid metabolism and central nervous system function. Amer J Med 1964;36:561-70.

2 Seegmiller JE, Rosenbloom FM, Kelley WN. Enzyme defect associated with a sex-linked human neurological disorder and excessive purine synthesis. Science 1967; 155:1682-4.

3 Kelley WN, Wyngarden JD. Clinical syndromes associated with hypoxanthine guanine phosphoribosyl transferase deficiency. In: Stanbury JB, Wyngarden JB, Fredrickson DS, Goldstein JL, Brown MS, eds. The metabolic basis of inherited disease. 5th edition. New York: McGraw-Hill, 1983:1115.
4 Dancis J, Yip LC, Cox RP, Piomelli S, Balis ME. Disparate enzyme activity in erythrocytes and leukocytes. $J$ Clin Invest $1973 ; 52: 2068-74$.

5 Emmerson BT, Thompson L. The spectrum of hypoxanthine-guanine phosphoribosyl transferase deficiency. QJ Med 1973;42:423-40.

- de Bruyn G. Hypoxanthine-guanine phosphoribosyl transferase deficiency. Hum Genet 1976;31:127-50.

Correspondence to $\operatorname{Dr} P$ C Holland, Renal Unit, The Hospital for Sick Children, Great Ormond Street, London WC1N 3JH.

Received 9 May 1983

\title{
Pulmonary eosinophilia associated with carbamazepine
}

\author{
J TOLMIE, C R STEER, AND A T EDMUNDS \\ Department of Paediatrics, Royal Hospital for Sick Children, Edinburgh
}

SUMMARY An 8 year old girl treated with carbamazepine developed eczema, wheeze, and evidence of pulmonary eosinophilia. Single dose challenge confirmed allergy to this drug. This reaction should be considered in patients being treated with carbamazepine who develop respiratory symptoms.

\section{Case report}

A Pakistani girl aged 8 years 11 months who had no past history of respiratory symptoms presented with cough and wheeze of two months' duration and a generalised eczematous rash that had been present for one month. She had been started on carbamazepine elixir 12 weeks previously for the treatment of temporal lobe seizures, and at the time of presentation was taking $300 \mathrm{mg}$ daily. There was no other notable past history or relevant family disorders apart from a maternal history of recurrent cough and wheeze treated with cromoglycate.

On examination the child was afebrile with a generalised itchy, eczematous rash. Her chest was of normal shape and she had widespread expiratory wheeze. Peak expiratory flow rate was $1201 / \mathrm{min}$ (expected $1901 / \mathrm{min}$ ). Chest radiographic examination showed collapse/consolidation of the right middle lobe accompanied by a diffuse increase in bronchovascular markings (Figure). Her blood count yielded an absolute eosinophilia of $11.07 \times$ $10^{9} / 1\left(11070 / \mathrm{mm}^{3}\right)(54 \%$ of $20 \cdot 5)$. Serum immunoglobulins including IgE were not raised, a complement screen was negative, and no immune complexes were detected in serum. Screening of urine, stool, and blood for fungal, parasitic, and bacterial infection was negative. Avian and fungal precipitin testing was negative and serum titres to mycoplasma and common respiratory viruses showed no evidence of recent infection. Prick tests to animal dander, pollen, and fungal allergens were negative.

Carbamazepine was stopped and she was given sodium valproate. The eosinophil count fell to $2.06 \times$ $10^{9} / 1\left(2060 / \mathrm{mm}^{3}\right)$ four days later. The wheeze and rash were treated with sodium cromoglycate, salbutamol, and chlorpheniramine. One month later there was no detectable wheeze or rash, her peak expiratory flow rate was $1901 / \mathrm{min}$, and no seizures were reported. All treatment except sodium valproate was stopped and she remained well except for one episode of wheeze associated with an upper respiratory infection.

Six months after presentation she was challenged with $20 \mathrm{mg}$ of oral carbamazepine elixir. Peak expiratory flow rate fell from $2001 / \mathrm{min}(100 \%$ expected) to $1001 / \mathrm{min}$, when measured $3 \frac{1}{2}$ hours after this dose and she also developed wheeze with pruritis. Over the next 24 hours her peak flow rate steadily improved to $1551 / \mathrm{min}$ and she became asymptomatic.

\section{Discussion}

Of the four similar adult cases described in reports, two were complicated by tuberculosis and mycoplasma infection. ${ }^{12} \mathrm{~A}$ third patient presented with respiratory symptoms after the drug had been withdrawn, ${ }^{3}$ and in the fourth, recovery was delayed until 6 months after drug treatment was stopped: a subsequent clinical challenge did not show air flow obstruction, although there was a worsening of asthmatic control on reintroducing carbamazepine at a therapeutic dose. ${ }^{4}$ In the child we describe, 